\title{
LncRNAs AK058003 and MVIH Overexpression in the Blood Samples of Iranian Breast Cancer Patients
}

\author{
Fatemeh Akhavan Attar ${ }^{1}$, Mana Oloomi ${ }^{2 *}$, Shiva Irani ${ }^{1}$, \\ Masoumeh Azizi $^{3}$ and Loabat Geranpayeh ${ }^{4}$
}

\author{
${ }^{1}$ Department of Biology, Science and Research Branch, Islamic Azad University, Tehran, Iran; ${ }^{2}$ Department \\ of Molecular Biology, Pasteur Institute of Iran, Tehran, Iran; ${ }^{3}$ Department of Molecular Medicine, Biotechnology \\ Research Center; Pasteur Institute of Iran, Tehran, Iran; ${ }^{4}$ Department of $4^{\text {th }}$ Surgery, Sina Hospital, Tehran, Iran
}

Received 18 January 2020; accepted 2 May 2020; published online 4 November 2020

\begin{abstract}
Background: LncRNAs are considered as novel biological regulators and potential cancer biomarkers. LncRNAs MVIH and AK058003 are associated with microvascular invasion in HCC. In BC, upregulated MVIH and AK058003 expression levels have been shown to promote cell proliferation, though LncRNA-AK058003 acts as a tumor suppressor in HCC. Methods: Blood samples were collected from 30 healthy women and 30 female BC patients. RNA was extracted from the blood of both groups, and cDNA was then synthesized. Real-time PCR was used to measure the expression level of LncRNA-AK058003 and MVIH. Results: The expression level of two LncRNAs in the blood samples of BC patients increased significantly compared with healthy individuals. The levels of AK058003 and $\mathrm{MVIH}$ were not associated with lymph node metastasis $(p=0.402$ and $p=0.39)$, tumor size $(p=0.76$ and $p=$ $0.461)$, and TNM stage ( $p=0.574$ and $p=0.711)$, respectively. Conclusion: As per our findings, LncRNA-AK058003 could serve as a suitable indicator for low stage of BC. In addition, the increased level of LnCRNA-MVIH could be considered as a biomarker for BC, which needs more evaluation in the future.
\end{abstract} DOI: 10.29252/ibj.25.2.93

Keywords: Breast cancer, Long noncoding RNA, Real-time PCR

Corresponding Author: Mana Oloomi

Department of Molecular Biology, Pasteur Institute of Iran, Tehran, Iran; Tel.: (+98-21) 66496578; E-mail: manaoloomi@yahoo.com

\section{INTRODUCTION}

$\mathrm{B}$ reast cancer is recognized as a high incident cancer and the leading cause of mortality among females, especially in developing countries ${ }^{[1,2]}$. In Iran, the incidence of $\mathrm{BC}$ is $21.4 \%$ among women, and $\mathrm{BC}$ accounts for $\sim 25 \%$ of the total number of cancers, equivalent to 22.4 people per one million of Iranian women ${ }^{[3]}$. Therefore, the early detection of $\mathrm{BC}$ is essential.

About $70 \%$ of Iranian women were diagnosed with a dangerous stage of $\mathrm{BC}$ due to the lack of organized screening and shortage of educational programs for the timely diagnosis of BC. Some of the most critical issues in the early diagnosis of $\mathrm{BC}$ are hormonal and environmental factors ${ }^{[4]}$.
An increasing number of novel treatment strategies have been expanded for BC, such as immunotherapy, gene therapy and targeted molecular therapy. Although satisfactory therapeutic results have been achieved, BC remains the most current cancer among women.

Non-coding RNAs, a new topic in cell biology, are defined as RNA transcripts that never translated into a protein (so-called 'non-coding') ${ }^{[5]}$. Many LncRNAs act in various pathological and physiological processes, such as differentiation, proliferation, and cellular metabolism ${ }^{[5]}$. Some of the LncRNAs have also vital roles in regulating oncogenic processes, including metastasis and apoptosis; however, the exact mechanisms of LncRNAs function require further investigation $^{[6,7]}$.

LncRNA-AK058003 has been reported to be 
upregulated in gastric cancer and supposed to promote cancer metastasis by targeting the $S N C G^{[8]}$. The unregulated LncRNA-AK058003 activates SNCG, which in turn stimulates the proliferation, invasion, and migration of $\mathrm{BC}^{[8,9]}$. The expression levels of LncRNA-AK058003 have been indicated to be downregulated in HCC tissues. In addition, LncRNAAK058003 binds human antigen $\mathrm{R}$, as an essential regulator of RNA metabolism, and acts as a precursor of miR-15a in regulating SNCG expression in $\mathrm{HCC}^{[10]}$.

A former study has reported an association between LncRNA-AK094613 and MVIH, and its expression levels can be upregulated in tumor tissues. In addition, LncRNA-MVIH can activate angiogenesis by inhibiting the secretion of phosphoglycerate kinase 1 , which is related to glucose metabolism pathway ${ }^{[11]}$. Another investigation has suggested that MVIH levels enhance in tumor tissues compared to adjacent normal tissues. The increased expression level was significantly correlated with tumor size, TNM stages, and lymph node metastasis. Furthermore, patients with the high levels of MVIH expression had poor prognosis, and the knockdown of MVIH expression by siRNA could inhibit cell proliferation and invasion ${ }^{[12]}$.

The aim of this study was to determine the gene expression of the LncRNAs, AK058003 and AK094613 (MVIH), in human blood BC specimens by qRT-PCR and to evaluate their relationship in terms of deregulation and clinical characteristics in Iranian BC patients.

\section{MATERIALS AND METHODS}

\section{Patients and specimens}

Thirty normal and $30 \mathrm{BC}$ patients were included in this study. The participants were chosen from different Hospitals (Sina, Farmaniyeh, and Moheb Kosar) in Tehran. Fresh blood samples $(5 \mathrm{ml})$ were collected and transferred to Pasteur Institute of Iran for RNA preparation. None of the patients had received preoperative cancer treatments, including radiotherapy or chemotherapy.

\section{RNA isolation and cDNA synthesis}

RNA samples were extracted from whole blood using a commercial kit (Jena Bioscience, Germany). The OD A260:A280 ratio and concentration of extracted RNAs were spectrometrically determined
(BioTek, USA). The cDNA synthesis was performed using the BioFact kit (Korea) as per manufacturer's instruction, in which $1 \mu$ l of Oligo(dT), $2 \mu$ l of RNA (5 $\mu \mathrm{g}), 7 \mu \mathrm{l}$ of double-distilled water, and $10 \mu \mathrm{l}$ of buffer were combined in a total reaction volume of $20 \mu \mathrm{l}$. The mixture was then incubated at $24{ }^{\circ} \mathrm{C}$ for $5 \mathrm{~min}$, followed by $50{ }^{\circ} \mathrm{C}$ for $30 \mathrm{~min}$, to synthesize the cDNA.

\section{qRT-PCR assay}

The expression levels of LncRNAs were quantified by Eva Green premix (WizPure qPCR Master). According to the protocol, $1 \mu$ of each forward and reverse primer, $2 \mu$ l of cDNA, $10 \mu$ of Master mix, and $6 \mu \mathrm{l}$ of water were mixed for universal analysis of DNA samples. The real-time PCR cycles were run in a Rotor-Gene Q machine (Corbett, Germany). The cycles were set as follows: an initial denaturation at $95{ }^{\circ} \mathrm{C}$ for $10 \mathrm{~min}$, followed by 40 cycles of $95{ }^{\circ} \mathrm{C}$ for $10 \mathrm{~s}$ (denaturation), $60{ }^{\circ} \mathrm{C}$ for $15 \mathrm{~s}$ (annealing), and $72{ }^{\circ} \mathrm{C}$ for $20 \mathrm{~s}$ (extension). The melting temperature was $72-$ $95{ }^{\circ} \mathrm{C}$. The sequences of primers used in this study are represented in Table 1, which manufactured by Microsynth, Germany. Each experiment was repeated two times, and $\beta$-actin was used as an internal control. Forward (5'-CTCTTCCAGCCTTCCTTCCT$\left.3^{\prime}\right)$ and reverse (5'-AGCACTCTGTTGGCGTACAG$\left.3^{\prime}\right)$ primers of $\beta$-actin were applied for the normalization of real-time PCR.

\section{Statistical analysis}

Data analysis between two groups and the comparison of multiple groups were performed by SPSS 16.0 using student's $t$-test and the one-way analysis of variance (ANOVA), respectively. The $t$-test also measured the relationship between the clinicopathological characters of patients and LncRNAs expression levels in human BC blood specimens. The LinReg PCR software (version 3, 2015) was applied to calculate the amount of $\mathrm{Ct}$ and efficiency for each chart. The relative gene expression level was calculated using the comparative $\mathrm{Ct}$ method $\left({ }^{2-} \Delta \Delta \mathrm{ct}\right)$ and the amount of fold change was determined using GraphPad Prism 5.0 (GraphPad Software, La Jolla, CA, USA). To draw a heatmap diagram, online software (CIMminer, One Matrix, NIH) was used. All the information was represented as mean \pm SD. $p$ values less than 0.05 were considered statistically significant.

Table1. Primers used in this study for real-time PCR

\begin{tabular}{lllc}
\hline LncRNA & Forward & Reverse & Length \\
\hline$M V I H$ & GAGACAGGATTTAGCCGTGTTG & AGCACTTTGGAAGGCTTAGACA & 84 \\
$A K 058003$ & GGGAACAAAGATGGTTTCTACGT & ACTGGTTCATAGTTAGGCTGGAT & 199 \\
\hline
\end{tabular}




\section{Ethical statement}

The above-mentioned sampling protocols were approved by the Research Ethics Committee of Pasteur Institute of Iran, Tehran, Iran (ethical code: IR.PII.REC.1397.008). Written informed consents were provided by all the participants.

\section{RESULTS}

The expression levels of LncRNAs in the blood of 30 $\mathrm{BC}$ patients and 30 healthy women were analyzed. The frequency of AK058003 and MVIH expression level and their correlation with the clinicopathological information of the patients are shown in Table 2.

Based on qRT-PCR analysis, AK058003 and MVIH expression levels were upregulated in $\mathrm{BC}$ samples (Fig. 1). The expression level of AK058003 and MVIH before and after normalization, calculated by LinReg PCR software, indicated a significant increase in the expression levels of both LncRNAs in BC blood specimens. In Figure 2, the relative expression level correlation of LncRNAs MVIH and AK058003 were calculated by Pearson and Spearman's method. To determine a suitable biomarker for cancer detection, rock marker (ROC curve) was also drawn in Figure 3, suggesting that AK058003 is more sensitive marker ( $p$ $<0.001$ ), but MVIH is a marker with more specificity.

In the heatmap diagram, the expression levels of LncRNAs AK058003 and MVIH in normal and BC patients are depicted in each sample (Fig. 4). The diagram also displays the expression levels of LncRNAs MVIH and AK058003 in each patient comparing the normal expression level and shows that AK058003 LncRNA expression is significantly higher in normal women.

\section{DISCUSSION}

Previous investigations have shown that LncRNAs play a crucial role in cancer organization and development. Further studies started to concentrate on the regulatory function of LncRNAs in cancer ${ }^{[13-18]}$. The expression levels of LncRNAs may facilitate novel drug targets and help to find diagnostic biomarkers for

Table 2. Clinicopathologic characteristics of patients and expression level of LncRNAs AK058003 and MVIH

\begin{tabular}{|c|c|c|c|c|c|c|c|c|}
\hline \multirow{2}{*}{$\begin{array}{l}\text { Clinicopathological } \\
\text { factors }\end{array}$} & \multirow{2}{*}{$\begin{array}{l}\text { Frequency } \\
\text { AK058003 }\end{array}$} & \multicolumn{2}{|c|}{ AK058003 } & \multirow{2}{*}{$\begin{array}{c}p \\
\text { value }\end{array}$} & \multirow{2}{*}{$\begin{array}{c}\text { Frequency } \\
\text { MVIH }\end{array}$} & \multicolumn{2}{|c|}{ MVIH } & \multirow{2}{*}{$\begin{array}{c}p \\
p \\
\text { value }\end{array}$} \\
\hline & & Low & High & & & Low & High & \\
\hline Age (year) & & & & & & & & 0.37 \\
\hline$<50$ & 53.4 & 2 & 14 & 015 & 53.4 & 6 & 24 & \\
\hline$>50$ & 46.6 & 1 & 13 & & 46.6 & 6 & 24 & \\
\hline Size $(\mathrm{cm})$ & & & & 0.76 & & & & 0.461 \\
\hline$<2.5$ & 60 & 2 & 17 & & 60 & 8 & 22 & \\
\hline$>2.5$ & 40 & 1 & 10 & & 40 & 5 & 25 & \\
\hline Type & & & & 0.557 & & & & 0.557 \\
\hline Invasive ductal carcinoma & 94 & 1 & 28 & & 94 & 8 & 22 & \\
\hline Invasive lobular carcinoma & 6 & 2 & & & 6 & 2 & 0 & \\
\hline Lymph nodes metastasis & & & & 0.402 & & & & 0.39 \\
\hline Positive & 46.6 & 1 & 13 & & 46.6 & 3 & 27 & \\
\hline Negative & 53.4 & 2 & 14 & & 53.4 & 9 & 21 & \\
\hline TNM stage & & & & 0.574 & & & & 0.711 \\
\hline 1 & 47 & 1 & 13 & & 47 & 7 & 23 & \\
\hline 2 & 23 & 1 & 6 & & 23 & 1 & 29 & \\
\hline 3 & 30 & 1 & 8 & & 30 & 2 & 27 & \\
\hline Diffrentiataion grade & & & & 0.829 & & & & 0.624 \\
\hline G1 & 26 & 1 & 7 & & 26 & 6 & 24 & \\
\hline $\mathrm{G} 2$ & 53 & 2 & 14 & & 53 & 5 & 25 & \\
\hline G3 & 21 & & 6 & & 21 & 1 & 29 & \\
\hline
\end{tabular}



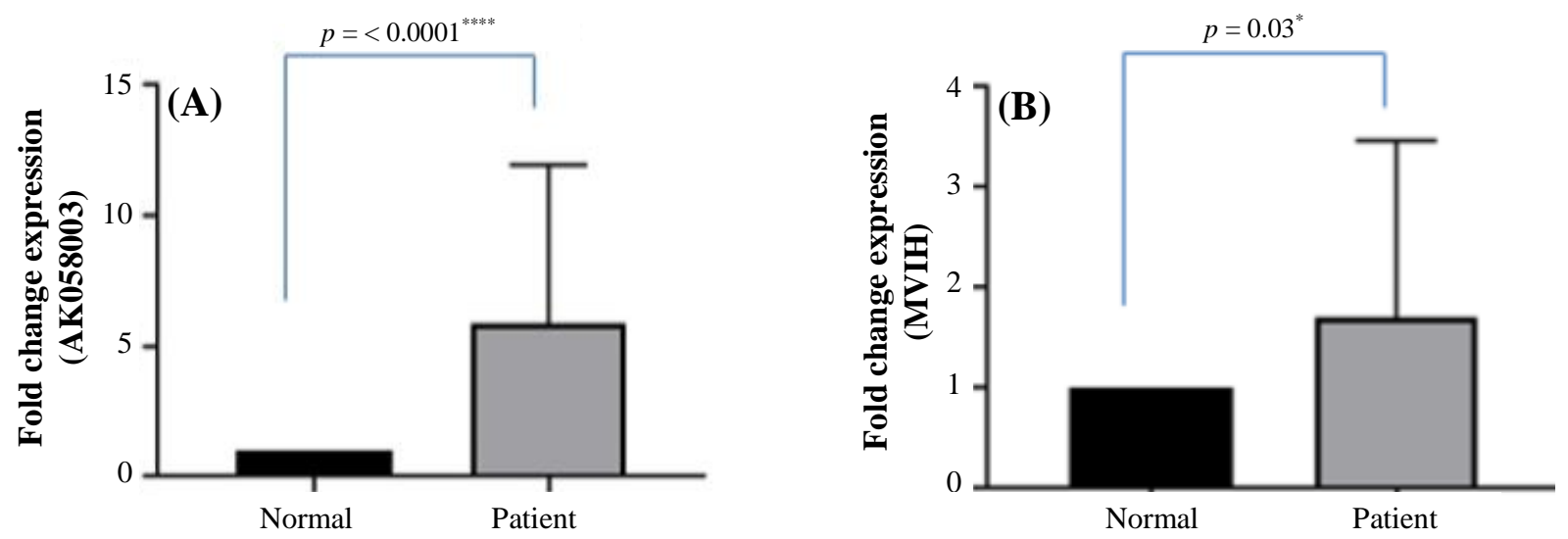

Fig. 1. The relative expression level of LncRNAs AK058003 and MVIH in the blood samples of 30 BC patients. LncRNAAK058003 (A) and LncRNA-MVIH (B) expressions were significantly higher in BC compared with normal blood samples. Also, the expression levels of MVIH and AK058003 were observed to be significant. $\Delta \mathrm{Ct}$ values were used to measure the gene expression, which was normalized by $\beta$-actin expression levels.

$\mathrm{BC}^{[18]}$. Cai et al. ${ }^{[19]}$ have demonstrated that the colon cancer-associated transcript 2 was considerably overexpressed in $\mathrm{BC}$ cell lines and $\mathrm{BC}$ tissues, and it was related to clinical prognostic factors. Zhen-Lin et $a{ }^{[20]}$ have also observed a significantly enhanced expression levels of Z38 in BC tissues compared with adjacent healthy tissues. This information denotes that $\mathrm{Z} 38$ is upregulated in $\mathrm{BC}$ tissues and may induce tumorigenesis of $\mathrm{BC}$ cells

LncRNA-H19 is one of the oncogenic LncRNAs that its expression has widely been investigated in blood samples $^{[21]}$. The expression levels of $\mathrm{H} 19$ in cancer biopsy specimens and plasma increased dramatically, which was significantly associated with the expression of estrogen and progesterone receptors and lymph node metastasis $^{[22]}$. However, Xiaoqin et al. ${ }^{[10]}$ have indicated that LncRNA-AK058003 acts as a tumor suppressor, inhibiting HCC cell growth and metastasis in vitro and in vivo LncRNA-AK058003 is a transcript with 1,197 nucleotides and located on the reverse strand of the chromosome $10 \mathrm{q} 22^{[23] .}$ Lei et al. ${ }^{[1]}$ have disclosed that the upregulation of MVIH in BC tissues, which were higher than adjacent noncancerous tissues, was correlated with Ki67 expression. Kumarswamy et $a l .{ }^{[24]}$ have reported that circulating LncRNAs were from the tissues, while the expression of MVIH and AK058003 were detected in blood. The results showed that the levels of MVIH and AK058003 in BC were much higher than their levels in the controls. Due to the existence of RNases, circulating LncRNAs are thought to be unstable ${ }^{[25]}$. In the present study, we assessed the MVIH and AK058003 levels in blood. Our result confirmed that circulating LncRNAs were stable, and we, for the first time, detected the expression of MVIH and AK058003 in blood for further analysis. Shin et al. ${ }^{[26]}$ measured the expression level of LncRNA-NEAT1 in the blood specimens of BC patient by qRT-PCR. Zhen-Lin et al. ${ }^{[20]}$ applied GAPDH and Liu et al. ${ }^{[27]}$ applied $\beta$-actin as the internal controls for qRT-PCR. We used both GAPDH and $\beta$ actin as controls, though $\beta$-actin showed more satisfactory result.

In this study, the ROC curves showed that AK058003 is more sensitive marker $(p<0.001)$ than MVIH for BC diagnosis. However, one limitation of the study was the sample size that was very limited, and our findings required to be validated with more cases. Herein, the correlations between LncRNAs (MVIH and AK058003) and between their expression level and different clinicopathological features of $\mathrm{BC}$ patients were analyzed. Our findings revealed that the high expression of LncRNAs AK058003 and MVIH

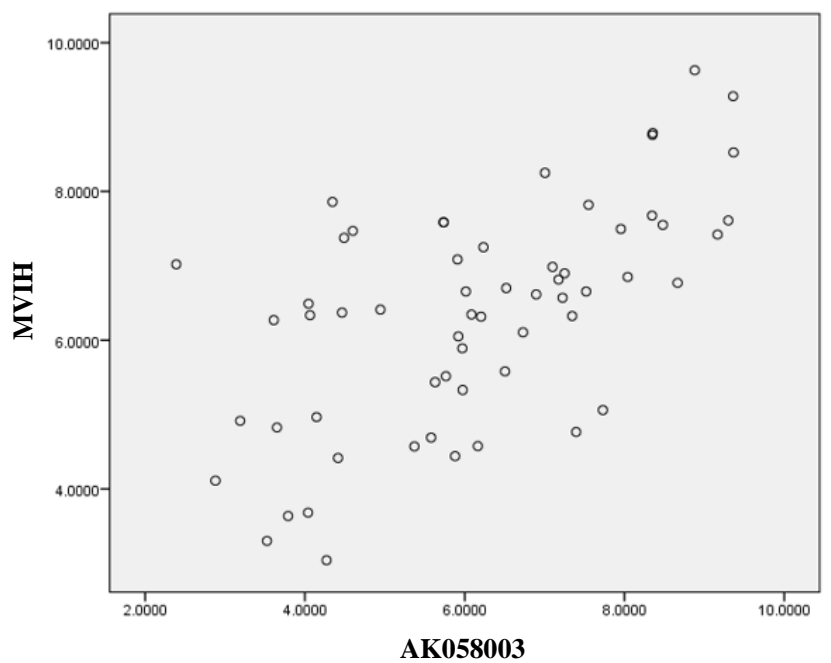

Fig. 2. The relative expression level of LncRNA-MVIH and LncRNA-AK058003 (Pearson correlation $=0.609^{* *}$ and Spearman's Rrho $\left.=0.599^{* * *}\right)$. 


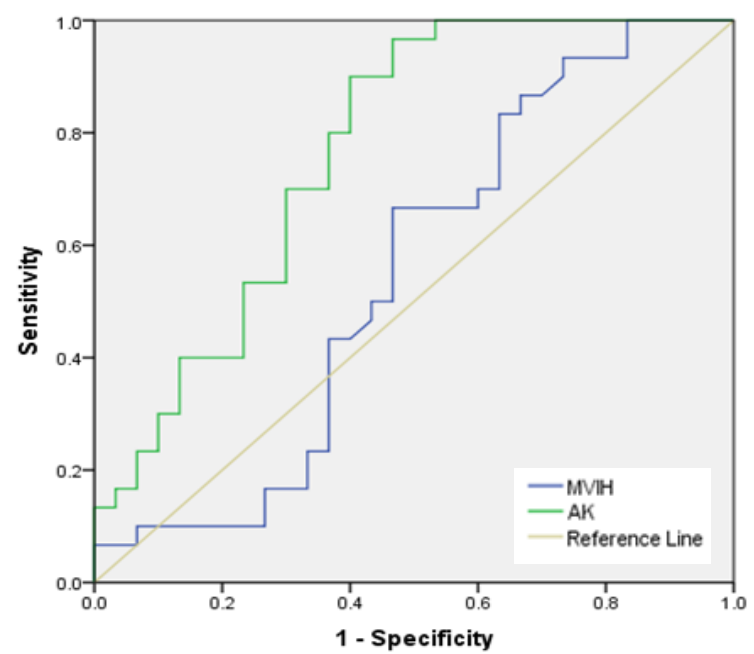

Fig. 3. ROC curve showing the sensitivity and specificity of LncRNAs AK058003 and MVIH.

were not related to stages, based on TNM, differentiation grade, and lymph node metastasis. However, He et al. ${ }^{[23]}$ found a close link between the expression of AK058003 and lymph node metastasis. This difference may correlate with the number of patients, though they are in low stage of BC.

In conclusion, the present study provides insights into the expression levels of AK058003 in relation to MVIH in the blood specimens of BC patients. For the first time in this study, the expression of LncRNAs AK058003 and MVIH demonstrated to be significantly higher in BC patients in comparison to controls. Further studies are needed to fully understand the molecular mechanisms of LncRNA application for diagnostic purposes in future.

\section{ACKNOWLEDGMENTS}

The authors would like to thank all patients who participated in the study. We have also special thanks to Dr. Zahra Pourramezan and Maryam Yousefpour for their help in performing this study, which has financially been supported by the Pasteur Institute of Iran, Tehran.

\section{CONFLICT OF INTEREST. None declared.}

\section{REFERENCES}

1. Lei B, Xu SP, Liang XS, Li YW, Zhang JF, Zhang GQ, Pang D. Long non-coding RNA MVIH is associated with poor prognosis and malignant biological behavior in breast cancer. Tumor biology 2016; 37(4): 52575264.

2. Akram M, Iqbal M, Daniyal M, Khan AU. Awareness and current knowledge of breast cancer. Biological research 2017; 50(1): 33 .

3. Bidgoli SA, Ahmadi R, Djamali avarhei M. Role of hormonal and environmental factors on early incidence of breast cancer in Iran. Science of the total environment 2010; 408(19): 4056-4061.
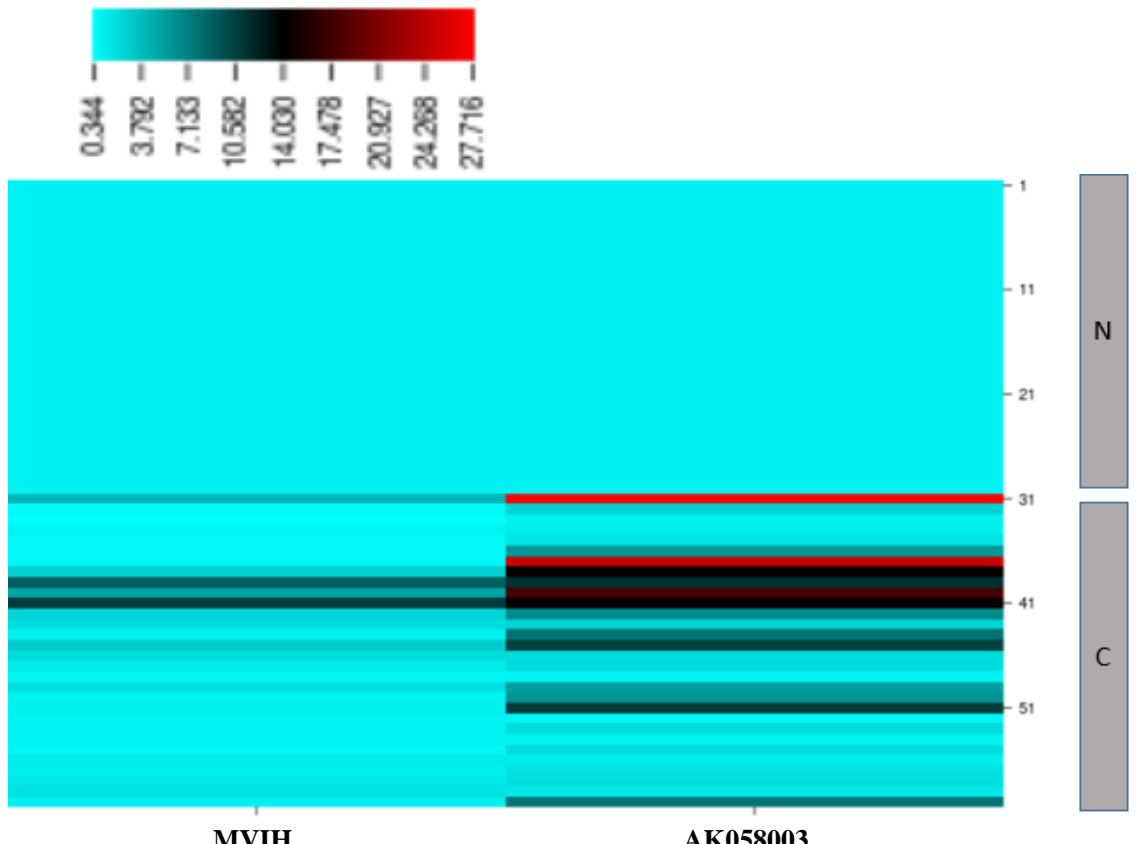

Fig. 4. Heatmap diagram of LncRNAs AK058003 and MVIH in normal and BC patients. N, normal; C, breast cancer patients. 
4. Cerk S, Schwarzenbacher D, Adiprasito JB, Stotz M, Hutterrer GC, Gerger A, Ling H, Callin GA, Pichler M. Current status of long non-coding RNAs in human breast cancer. International journal of molecular sciences 2016; 17(9): 1485.

5. Brunner AL, Beck AH, Edris B, Sweeney RT, Zhu SX, Li R, Montgomery K, Varma S, Gilks T, Guo X, Foley JW, Witten DM, Giacomini CP, Flynn RA, Pollack JR, Tibshirani R, Chang HY, van de Rijn M, West RB. Transcriptional profiling of long non-coding RNAs and novel transcribed regions across a diverse panel of archived human cancers. Genome biology 2012; 13(8): R75.

6. Zhang K, Luo Z, Zhang Y, Song X, Zhang L, Wu L, Liu J. Long non-coding RNAs as novel biomarkers for breast cancer invasion and metastasis. Oncology letters 2017; 14(2): 1895-1904.

7. Braconi C, Patel T. Non-coding RNAs as therapeutic targets in hepatocellular cancer. Current cancer drug targets 2012; 12(9): 1073-1080.

8. Wang Y, Liu X, Zhang H, Sun L, Zhou Y, Jin H, Zhang H, Zhang H, Liu J, Guo H, Nie Y, Wu K, Fan D, Zhang H, Liu L. Hypoxia-inducible IncRNA-AK058003 promotes gastric cancer metastasis by targeting $\gamma$ synuclein. Neoplasia 2014; 16(12): 1094-1106.

9. Wang CY, Hua L, Yao KH, Chen JT, Zhan JJ, Hu JH. Long non-coding RNA CCAT2 is up-regulated in gastric cancer and associated with poor prognosis. International journal of clinical and experimental pathology 2015; 8(1): 779-785.

10. Xiaoqin H, Zheng Y, Zhang Y, Gan Y, Zhou Y, Liang $\mathrm{H}, \mathrm{Wu} \mathrm{D}, \mathrm{Ge} \mathrm{W}$, Deng J, Xu X. Long non-coding RNA AK058003, as a precursor of miR-15a, interacts with HuR to inhibit the expression of Y-synuclein in hepatocellular carcinoma cells. Oncotarget 2017; 8(6): 9451-9465.

11. Yuan SX, Yang F, Yang Y, Tao QF, Zhang J, Huang G, Yang Y, Wang RY, Yang S, Huo XS, Zhang L, Wang F, Sun SH, Zhou WP. Long noncoding RNA associated with microvascular invasion in hepatocellular carcinoma promotes angiogenesis and serves as a predictor for hepatocellular carcinoma patients' poor recurrence-free survival after hepatectomy. Hepatology 2012; 56(6): 2231-2241.

12. Nie F-q, Zhu Q, Xu T-p, Zou Yf, Xie M, Sun M,Xia R, $\mathrm{Lu} \mathrm{KH}$. Long non-coding RNA MVIH indicates a poor prognosis for non-small cell lung cancer and promotes cell proliferation and invasion. Tumor biology 2014; 35(8):7587-7594.

13. Weiss-Salz I, Harlap S, Friedlander Y, Kaduri L, LevyLahad E, Yanetz R, Dutsh L, Hochner H, Paltiel O. Ethnic ancestry and increased paternal age are risk factors for breast cancer before the age of 40 years. European journal of cancer prevention 2007; 16(6): 549-554.

14. Spizzo R, Almeida MIe, Colombatti A, Calin GA. Long non-coding RNAs and cancer: a new frontier of translational research? Oncogene 2012; 31(43): 45774587.
15. Yang Z, Zhou L, Wu LM, Lai MC, Xie HY, Zhang F, Zheng SS. Overexpression of long non-coding RNA HOTAIR predicts tumor recurrence in hepatocellular carcinoma patients following liver transplantation. Annals of surgical oncology 2011; 18(5): 1243-1250.

16. Gerasimova E, Audit B, Roux SG, Khalil A, Gileva O, Françoise A, Naimark O, Arneodo A. Wavelet-based multifractal analysis of dynamic infrared thermograms to assist in early breast cancer diagnosis. Frontiers in physiology 2014; 5: 176.

17. Hauptman N, Glavač D. Long non-coding RNA in cancer. International journal of molecular sciences 2013; 14(3): 4655-4669.

18. Shi Y, Li J, Liu Y, Ding J, Fan Y, Tian Y, Wang L, Lian Y, Wang K, Shu Y. The long noncoding RNA SPRY4IT1 increases the proliferation of human breast cancer cells by upregulating ZNF703 expression. Molecular cancer 2015; 14: 51.

19. Cai, Jing H, Zhang D. Long noncoding RNA CCAT2 promotes breast tumor growth by regulating the Wnt signaling pathway. Oncotargets and therapy 2015; 8: 2657-2664.

20. Zhen-Lin N, Wang YS, Mei YP, Lin X, Zhang GX, Sun HL, Wang YL, Xia YX, Wang SK. Prognostic significance of long noncoding RNA Z38 as a candidate biomarker in breast cancer. Journal of clinical laboratory analysis 2018; 32(1): e22193.

21. Zemel S, Bartolomei MS, Tilghman SM. Physical linkage of two mammalian imprinted genes, H19 and insulin-like growth factor 2. Nature genetics 1992; 2(1): 61-65.

22. Collette J, Le Bourhis X, Adriaenssens E. Regulation of human breast cancer by the long non-coding RNA H19. International journal of molecular sciences 2017; 18(11): 2319.

23. He K, Wang $\mathrm{P}$. Unregulated long non-coding RNA-AK058003 promotes the proliferation, invasion and metastasis of breast cancer by regulating the expression levels of the $\gamma$-synuclein gene. Experimental and therapeutic medicine 2015; 9(5):1727-1732.

24. Kumarswamy R, Bauters C, Volkmann I, Maury F, Fetisch J, Holzmann A, Lemesle G, de Groote P, Pinet F, Thum T. Circulating long noncoding RNA, LIPCAR, predicts survival in patients with heart failure. Circulation research 2014; 114(10): 1569-1575.

25. Tsui NB, Ng EK, Lo YMD. Stability of endogenous and added RNA in blood specimens, serum, and plasma. Clinical chemistry 2002; 48(10): 1647-1653.

26. Shin, VY, Chen J, Cheuk IWY, Siu MT, Ho CW, Wang $\mathrm{X}$, Jin $\mathrm{H}$, Kwong A. Long non-coding RNA NEAT1 confers oncogenic role in triple-negative breast cancer through modulating chemoresistance and cancer stemness. Cell death and disease 2019; 10: 270.

27. Liu M, Gou L, Xia J, Wan Q, Jiang Y, Sun S, Tang M, He T, Zhang Y. LncRNA ITGB2-AS1 could promote the migration and invasion of breast cancer cells through up-regulating ITGB2. International journal of molecular sciences 2018; 19(7): 1866. 